\title{
Nanocomposite-forming solutions based on cassava starch and laponite: Viscoelastic and rheological characterization
}

\author{
Germán Ayala Valencia a,*, Izabel Cristina Freitas Moraes a , Loic Hugues Gilles Hilliou ${ }^{\text {b }}$, \\ Rodrigo Vinicius Lourenço ${ }^{a}$, Paulo José do Amaral Sobral ${ }^{\text {a,* }}$ \\ a Department of Food Engineering, Faculty of Animal Science and Food Engineering, University of São Paulo, Pirassununga, SP, Brazil \\ ${ }^{\mathrm{b}}$ IPC/I3N, Department of Polymer Engineering, University of Minho, Campus de Azurém, Portugal
}

\section{A R T I C L E I N F O}

\section{Article history:}

Received 13 February 2015

Received in revised form 1 June 2015

Accepted 3 June 2015

Available online 4 June 2015

\section{Keywords:}

Biodegradable films

Nanoclay

Nanoparticles

Newtonian behavior

Non-Newtonian behavior

Thermal transition

\begin{abstract}
A B S T R A C T
Nanocomposites-forming solutions (NFS) based on cassava starch and laponite were prepared and next characterized by means of dynamic oscillatory and steady shear rheological tests to evaluate their ability to be processed by knife coating. The effects of speed (rpm) and homogenization time on the laponite dispersion characteristics were first analyzed. Laponite dispersions were affected by both process parameters. High speed (rpm), i.e. 20,000 or $23,000 \mathrm{rpm}$ for $30 \mathrm{~min}$ or prolonged homogenization time $(10,000 \mathrm{rpm} \leqslant$ speed agitation $\leqslant 23,000 \mathrm{rpm}$, for $60 \mathrm{~min})$ led to high $\zeta$-potential values, with laponite particles size $<80 \mathrm{~nm}$. With addition of laponite nanoparticles to cassava starch dispersion, an evident transition in NFS from liquid-like viscous to solid-like elastic behavior was observed. Rheological results indicated that laponite nanoparticles induced new interactions with starch chains allowing to obtain a network structure typical of a semi-rigid gel which shows some spread ability.
\end{abstract}

(c) 2015 Published by Elsevier Ltd.

\section{Introduction}

Nanomaterials are characterized by having at least one dimension of its particles in nanometric dimension, i.e. between 1 and $100 \mathrm{~nm}$ (Aouada et al., 2011). When the particle size is equivalent to the dimension of a molecule, the atomic and molecular interactions can have a significant influence on the macroscopic properties of that material (Aouada et al., 2011; Jorge et al., 2014). Thus, this behavior is associated with the specifics size of nanomaterials such as their high surface to volume ratio (Hassanabadi and Rodrigue, 2012).

Among nanomaterials, there are some thin and flexible materials based on biopolymers charged with nanoparticles. This is a consequence of an approach to improve the mechanical and barrier properties of conventional polymer and biopolymers based films, then producing composites in nanoscale or nanocomposites (Tang and Alavi, 2012; Jorge et al., 2014). Nanocomposites should exhibit a notable enhancement in rigidity and resistance, reduced water vapor and gas permeability, and lower flammability (Tang and Alavi, 2012).

\footnotetext{
* Corresponding authors.

E-mail addresses: gayalav1230@gmail.com (G.A. Valencia), pjsobral@usp.br (P.J.d.A. Sobral).
}

In the biopolymer films technology for food applications, the montmorillonite is the nanoparticle most used in studies on development of films nanocomposites. It has been used to load films based on gelatin (Flaker et al., 2015), zein (Park et al., 2012), starch (Cyras et al., 2008), chitosan (Kasirga et al., 2012), among others. A nanoparticle not so much studied in biopolymer based film is the laponite. Laponite or hydrous sodium lithium magnesium silicate $\left(\mathrm{Na}_{0.7}^{+}\left[\left(\mathrm{Si}_{8} \mathrm{Mg}_{5.5} \mathrm{Li}_{0.3}\right) \mathrm{O}_{20}(\mathrm{OH})_{4}\right]^{-0.7}\right)$ is a synthetic hectorite clay with particle disk-shape with a thickness of $1 \mathrm{~nm}$, and a diameter of approximately of $25 \mathrm{~nm}$ (Nicolai and Cocard, 2000; Cummins, 2007). Laponite disk have an octahedral configuration with $\mathrm{Mg}^{2+}$ ions in the octahedral sites and also $\mathrm{Li}^{+}$ions in minor amount and $\mathrm{Na}^{+}$ions in the interlayer domain (Perotti et al., 2011). In water, laponite disk hydrates and swells to form clear colloidal dispersions with high stability due to its negative surface charge density of 0.014 e- $/ \AA^{2}$ (Nicolai and Cocard, 2000; Herrera et al., 2004).

Laponite has been broadly used in agriculture, construction, personal care, surface coatings and polymer industry (Kumar et al., 2008). Shibayama et al. (2004) reported that the laponite addition in hydrogels based of $\mathrm{N}$-isopropylacrylamide led a notable high strength and elongation at break in excess of $1000 \%$. Similar results were reported by Haraguchi et al. (2005) and Haraguchi and $\mathrm{Li}$ (2006) for hydrogels reinforced with laponite. Most recently, Chung et al. (2010), Aouada et al. (2011), Tang and Alavi (2012) and Perotti et al. (2014) demonstrated that laponite can improve the 
resistance, rigidity, water resistance and water vapor permeability in films based on corn starch, then laponite could be a compatibilizer and cross-linking agent between starch chains.

Besides, the laponite has attracted attention of researcher because its rheological behavior in high concentrated solution in water, which behaves as dilatant fluids (Abou et al., 2003; Joshi et al., 2008). Nevertheless, rheological studies on more diluted solutions of laponite have been not studied, neither on film-forming solutions containing that nanoparticle.

Rheological analyzes of nanocomposite-forming solutions can help to understand the structure-property relations between polymer and nanocomposites (Hassanabadi and Rodrigue, 2012), as well as to optimize the nanostructured film production, specially the casting and spreading techniques (Jorge et al., 2014) since rheology studies interplay between flow and material properties. No information about the effect of laponite on the rheological properties in starch filmogenic solution was reported to date. Hence, this work aimed to study the effect of laponite concentration on the viscoelastic and rheological behavior of nanocomposite-forming solutions (NFS) based on cassava starch by means of dynamic oscillatory and steady shear tests.

\section{Materials and methods}

\subsection{Materials}

Cassava starch (humidity $=10.70 \pm 0.10 \%$ wet basis) was purchased from local market in Pirassununga city (São Paulo, Brazil) and was used as biopolymer for nanocomposite-forming solutions (NFS). Glycerol was supplied by Synth company (São Paulo, Brazil) and used as plasticizer. Laponite RD (Southerm Clay Products Inc. Reference number 23224) was used as nanoparticle. Distilled water was used to disperse laponite and as a solvent in NFS based on cassava starch. Deionized water and potassium hydroxide $(\mathrm{KOH}) 1 \mathrm{M}$ were used in the sample preparation for particle size distribution and $\zeta$-potential analysis respectively.

\subsection{Characterization of laponite powder}

Laponite morphology was analyzed using low vacuum scanning electron microscopy (LV-SEM, TM-3000, HITACHI, Japan) at an accelerated voltage of $15 \mathrm{kV}$. Before analysis, laponite powder was conditioned under vacuum by $12 \mathrm{~h}$ and then fixed on aluminum stubs by means of conductive carbon tape. No additional preparation was necessary for analysis using this LV-SEM (Flaker et al., 2015). Energy dispersive spectroscopy (EDS) of laponite was analyzed in the same equipment.

\subsection{Production of laponite dispersions}

To disperse laponite in distilled water, $1 \mathrm{~g}$ of laponite was added to $99 \mathrm{~g}$ of distilled water and then dispersed under vigorous stirring using a high speed homogenizer (ultraturrax, Ika, model T25) at room temperature. To study the effect of control process variables in ultraturrax, comparative experiments were carried out to examine the effect of different speed $(10,000 ; 15,000$; 20,000 and $23,000 \mathrm{rpm}$ ) and dispersion time (30 and $60 \mathrm{~min}$ ) on the quality of laponite dispersion in distilled water.

\subsection{Characterization of laponite dispersions}

The $\mathrm{pH}$ of laponite dispersions was analyzed by means of a digital pH meter (PG1400 Gehaka). Dynamic light scattering (DLS) measurements were performed using a Zetaplus equipment (Brookhaven Instrument Company, EUA) to determine the particle size distribution and surface charge ( $\zeta$-potential). These determinations were obtained at room temperature. Laponite dispersions were stored at $4{ }^{\circ} \mathrm{C}$ until use.

Atomic force microscopy (AFM) images were obtained using a SolverNext (NT-MDT, Russia). Laponite dispersions were diluted to a designed concentration, and then $10 \mu \mathrm{L}$ were pipetted onto a piece of freshly cleaved mica sheet. The dispersion was then allowed to evaporate in an enclosed Petri dish under ambient conditions (40\% relative humidity) for $24 \mathrm{~h}$ (Balnois et al., 2003). The nanostructures were characterized using the semi-contact mode in AFM with a resonance frequency of $240 \mathrm{kHz}$, force contact of $11.8 \mathrm{~N} / \mathrm{m}$ and scan speed $0.3 \mathrm{~Hz}$.

The rheological properties of laponite dispersions were obtained at $25^{\circ} \mathrm{C}$ with a rheometer (AR2000 Advanced Rheometer, TA Instruments, New Castle DE, EUA), using a double concentric cylinder geometry (internal radius $=16.0 \mathrm{~mm}$, external radius $=17.5 \mathrm{~mm}$, height $=53 \mathrm{~mm}$ and gap $=2000 \mu \mathrm{m}$ ). For each test, $12 \mathrm{~mL}$ of laponite dispersions was used. The dispersions were analyzed by applying steady shear rates ranging from 0.1 to $100 \mathrm{~s}^{-1}$, being submitted to two shear rate sweeps, increasing then decreasing, with duration of 2 min each (Moraes et al., 2009; Jorge et al., 2014). All resulting flow curves were measured at least three times for each laponite dispersion.

\subsection{Production of NFS based on cassava starch and laponite}

The NFS were produced using $\left(C_{c s}\right) 2$ and $4 \mathrm{~g}$ of cassava starch/100 $\mathrm{g}$ of NFS, and $30 \mathrm{~g}$ glycerol/100 $\mathrm{g}$ of cassava starch. Laponite dispersed in distilled water at $20,000 \mathrm{rpm}$ for $30 \mathrm{~min}$ (see preliminary dispersion tests reported in Section 3.2) was added in different concentrations $\left(C_{\text {Lap }}\right): 0,5,10,15$ and 20 g laponite/100 g cassava starch. Distilled water was added to complete $100 \mathrm{~g}$ of NFS. The NFS were heated at $95 \pm 1{ }^{\circ} \mathrm{C}$ for $30 \mathrm{~min}$ to promote starch gelatinization (Chen et al., 2009), and later cooled down to $25^{\circ} \mathrm{C}$ within $30 \mathrm{~min}$, covered with a preservative film to minimize the loss of moisture during heating and cooling (Che et al., 2008).

\subsection{Rheological characterization of NFS}

All rheological tests were carried out with the same rheometer as in Section 2.4.

\subsubsection{Dynamic oscillatory characterization}

For all tests, nearly $4 \mathrm{~mL}$ NFS were loaded in the cone and plate geometry (cone angle $4^{\circ}, 60 \mathrm{~mm}$ diameter) of the rheometer. Right after loading, a pre-shear at a shear rate of $1 \mathrm{~s}^{-1}$ was applied during 1 min to erase any flow history and rejuvenate the NFS, thus ensuring test reproducibility. Temperature was controlled using a Peltier system and the water evaporation in NFS was avoided using mineral oil and a solvent trap accessory (Jorge et al., 2014). All results were analyzed using the software Rheology Advantage Data Analysis V.5.3.1 (TA Instrument).

Firstly, the linear viscoelastic region was determined at $25^{\circ} \mathrm{C}$ by performing small amplitude oscillatory strain (SAOS) sweep tests on all NFS, and using strain values between $0.01 \%$ and $100 \%$ and $1 \mathrm{~Hz}$ of frequency (Moraes et al., 2009). From the results of these tests, a strain amplitude of $1 \%$, within the linear viscoelastic domain in NFS, was chosen to perform all remaining SAOS tests. A time sweep test at $1 \mathrm{~Hz}$ on new NFS loaded samples was first performed to check for sample equilibrium after loading and pre-shear. Then, a stress sweep test was performed at $1 \mathrm{~Hz}$ and for stress values between 0.1 and $180 \mathrm{~Pa}$, or a frequency sweep test for frequency values between 0.01 to $10 \mathrm{~Hz}$ was performed. All characterizations were realized at least three times for each NFS. 


\subsubsection{Steady shear properties}

Flow curves of NFS were performed using two different geometries. The NFS produced with $2 \mathrm{~g}$ of cassava starch/100 $\mathrm{g}$ of NFS were analyzed using a concentric cylinder geometry (internal radius $=14 \mathrm{~mm}$, external radius $=15 \mathrm{~mm}$, height $=42 \mathrm{~mm}$ and gap $=1000 \mu \mathrm{m}$ ). For each test, $13 \mathrm{~mL}$ of NFS was used. The NFS produced with $4 \mathrm{~g}$ of cassava starch were analyzed using parallel plate geometry $(60 \mathrm{~mm}$ diameter, gap $=1000 \mu \mathrm{m})$. The NFS were studied in a shear rate range between 0.1 and $200 \mathrm{~s}^{-1}$, using the following experimental protocol: firstly an increasing shear rate sweep was applied to erase any flow history and rejuvenate the NFS, thus ensuring test reproducibility. Later a decreasing and an increasing shear rate sweeps were applied to study the rheological behavior of NFS. Each shear rate sweep had a duration of 2 min (Moraes et al., 2009; Jorge et al., 2014). All characterizations were realized at least three times for each NFS.

\subsection{Statistical analyses}

An analysis of variance (ANOVA) and Tukey test of multiple comparisons were accomplished with a significance level of $5 \%$ (SAS software). All fitting of the models to data were done using Origin Software.

\section{Results and discussions}

\subsection{Characterization of laponite powder}

Scanning electron micrographs displayed in Fig. 1 show that laponite is made of micrometer large agglomerates with irregular size and shape. The magnified SEM picture (see Fig. $1 \mathrm{~b}$ ) reveals that agglomerates consist of stacked plate-like objects. A similar observation was reported by Bippus et al. (2009) who attributed the aggregate structure to the stacking of elementary laponite disks. The chemical analysis performed with EDS gives the following mean chemical composition: $\mathrm{SiO}_{2}, 68.6 \%$; $\mathrm{MgO}, 28.9 \%$; and $\mathrm{Na}_{2} \mathrm{O}$, $2.5 \%$, in agreement with the chemical composition reported by Levitz et al. (2000), for the same raw material.

\subsection{Characterization of laponite dispersions}

Ultraturrax proved to be an efficient method to disrupt the aggregates. The particle size distribution obtained by laser diffraction indicates two distinct populations (bi-modal distribution) for all speed and homogenization time tested in ultraturrax (Fig. 2). Low speed and homogenization time, i.e. 10,000 and 15,000 rpm for 30 min give two particle populations between 15-26 and 114-172 nm (Fig. 2a). A notable decrease in particle size of both populations was observed when prolonged treatment time (60 min) or larger ultraturrax speed $(\geqslant 20,000 \mathrm{rpm}$ ) was employed
(Fig. 2b-d). The best speed and homogenization time combination was 20,000 rpm/30 min which gives nanometric particles of roughly $4 \mathrm{~nm}$ and $40 \mathrm{~nm}$, as longer treatment time is not accompanied by any further particle size reduction. The bi-modal distribution reported in Fig. 2 together with the size ranges are in agreement with earlier reports on laponite (Daniel et al., 2007; Bippus et al., 2009) which assigned the particles to aggregates of elementary laponite disks.

Additional information on particle size and shape is provided by the AFM images presented in Fig. 3. Plate like objects with sizes very similar to those measured with LDS were pictured. Height profile from AFM image (Fig. 3b) confirmed the internal structure of the aggregates and elementary particle disk-shape with thickness of approximately $1 \mathrm{~nm}$ and a diameter of $24 \mathrm{~nm}$ as reported in the literature (Nicolai and Cocard, 2000; Cummins, 2007) were observed. Despite the high dilution (1:100), a large amount of laponite particles shows up in the AFM images.

The stability of laponite dispersions can be evaluated by means of $\zeta$-potential and $\mathrm{pH}$ determination. The $\zeta$-potential values in laponite dispersions were sensible to the speed and homogenization time (Table 1). High speed (rpm), i.e. 20,000 or 23,000 rpm for $30 \mathrm{~min}$ or prolonged homogenization time $(10,000 \mathrm{rpm} \leqslant$ speed agitation $\leqslant 23,000 \mathrm{rpm}$, for $60 \mathrm{~min})$ led to high $\zeta$-potential values. This is in harmony with results reported by Jorge et al. (2014) who noted that the superficial charge is related with surface area, hence more negative $\zeta$-potential values are correlated with smaller particles. No effects of speed or homogenization time on $\mathrm{pH}$ can be inferred from the data collected in Table 1 . The $\zeta$-potential $(<-34 \mathrm{mV}$ ) and $\mathrm{pH}$ (approximately 10$)$ values (Table 1) suggest that laponite dispersion have high stability, as reported by Cummins (2007).

According to results of rheological essays, the laponite dispersions showed a Newtonian behavior. This Newtonian character of the laponite dispersions measured by ramping up or down the shear rates suggests that flow does not induce any laponite aggregation for the tested concentration and shear rate range. The agitation speed and time do not impact on $\eta$ values (Table 1 ).

\subsection{Rheological characterization of NFS}

\subsubsection{Dynamic oscillatory characterization}

Strain sweep tests revealed that at $25{ }^{\circ} \mathrm{C}$ all NFS showed a $0.2-$ $10 \%$ strain range where $G^{\prime}$ and $G^{\prime \prime}$ moduli remain constant, thus indicating a linear viscoelastic domain (Fig. 4).

The time dependence of storage modulus $\left(G^{\prime}\right)$ measured after loading the sample into the shearing geometry and applying a pre-shear rate of $1 \mathrm{~s}^{-1}$ during $1 \mathrm{~min}$ is shown in Fig. 5 for all NFS. The results reveal a strong effect of clay particles on the elasticity of the NFS as $G^{\prime}$ values increased with $C_{\text {Lap }}$. More importantly, these results indicate that all samples achieved equilibrium conditions
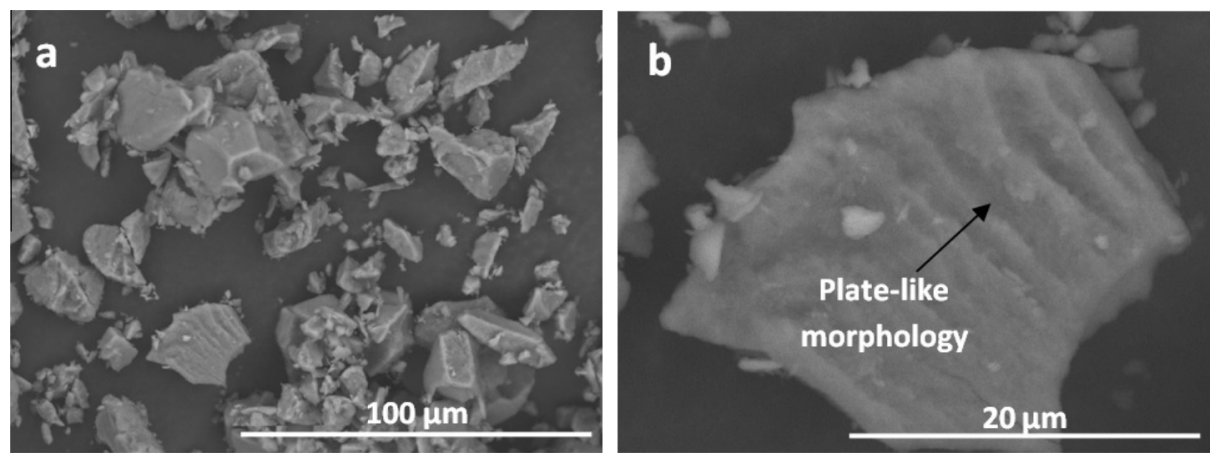

Fig. 1. Scanning electron micrographs of raw laponite: $1000 \times(a)$ and $5000 \times($ b) magnification. 

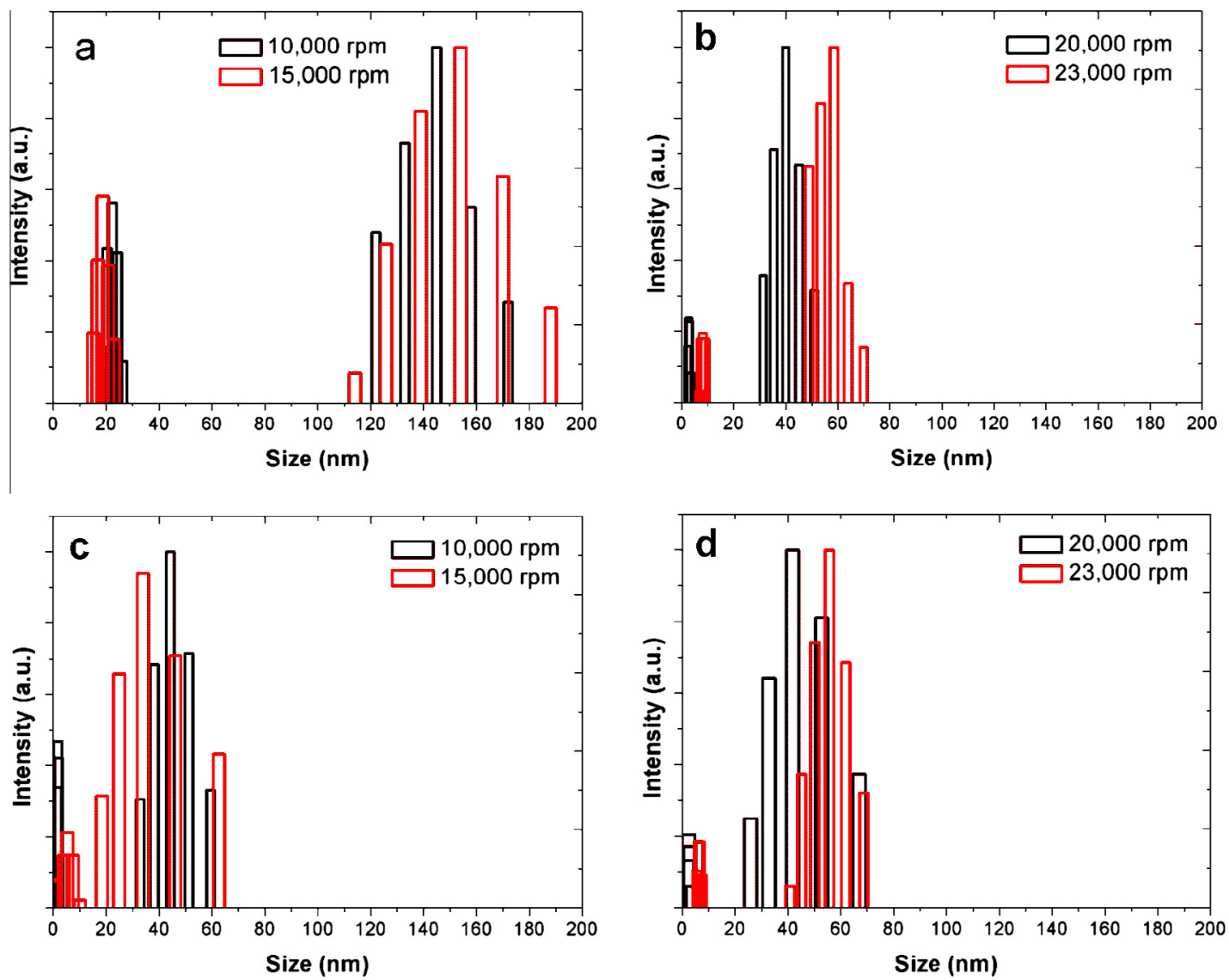

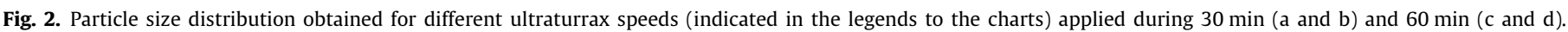
Intensity $(\%)$ is based on number particles.
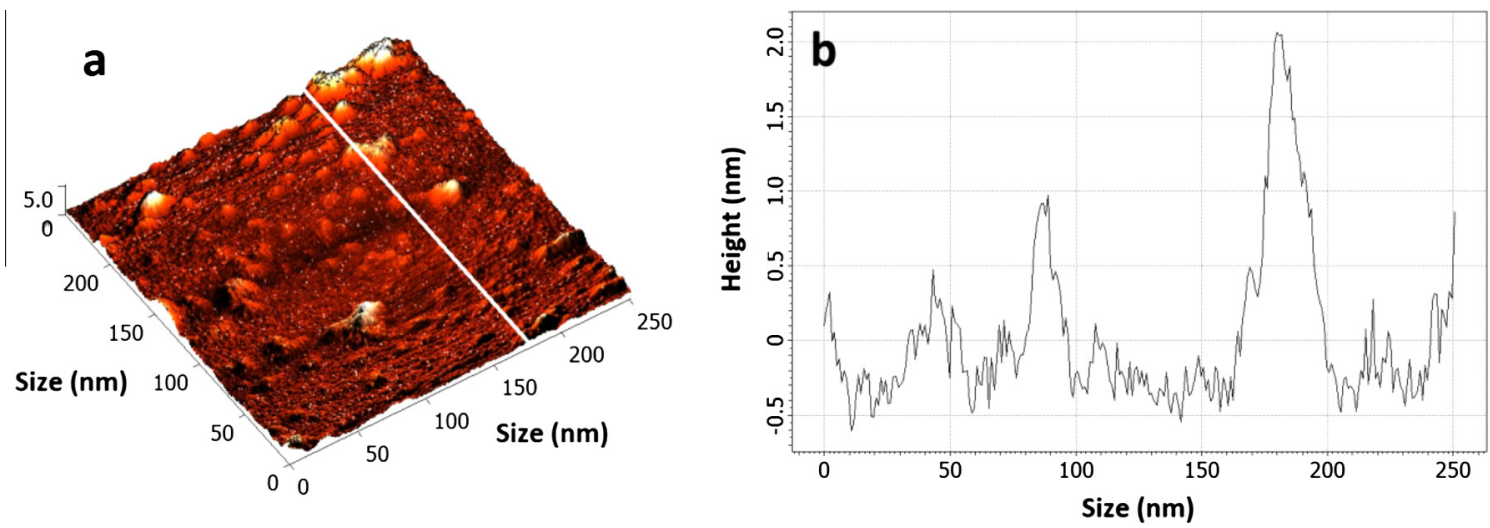

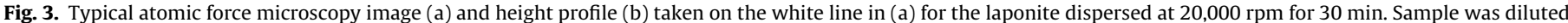
at $1: 100$ in filtered and distilled water.

Table 1

$\zeta$-potential, $\mathrm{pH}$ and viscosity values ${ }^{*}$ of laponite dispersions in water.

\begin{tabular}{|c|c|c|c|c|c|c|}
\hline \multirow[t]{2}{*}{ Speed $\left(\times 10^{-3}\right)(\mathrm{rpm})$} & \multicolumn{2}{|l|}{$\zeta$-potential $(\mathrm{mV})$} & \multicolumn{2}{|l|}{$\mathrm{pH}$} & \multicolumn{2}{|c|}{ Viscosity $\left(\mathrm{Pa} \mathrm{s} \times 10^{4}\right)$} \\
\hline & 30 min & $60 \mathrm{~min}$ & $30 \min$ & $60 \mathrm{~min}$ & $30 \mathrm{~min}$ & $60 \mathrm{~min}$ \\
\hline 10 & $-34.87 \pm 1.95^{\mathrm{B}}$ & $-44.20 \pm 1.36^{\mathrm{A}}$ & $10.60 \pm 0.04^{\mathrm{A} a}$ & $10.60 \pm 0.06^{\mathrm{A}}$ & $10.70 \pm 0.28$ & $11.01 \pm 0.06$ \\
\hline 15 & $-35.49 \pm 0.03^{\mathrm{B} b}$ & $-43.53 \pm 1.41^{\mathrm{A} a}$ & $10.20 \pm 0.06^{\mathrm{B} \mathrm{a}}$ & $10.20 \pm 0.04^{\mathrm{Ba}}$ & $10.69 \pm 0.30$ & $11.03 \pm 0.01$ \\
\hline 20 & $-39.90 \pm 4.50^{\mathrm{AB}}$ & $-43.78 \pm 1.24^{\mathrm{A}}$ & $10.00 \pm 0.03^{C}$ & $10.00 \pm 0.01^{\mathrm{c}}$ & $11.05 \pm 0.07$ & $11.03 \pm 0.02$ \\
\hline 23 & $-45.71 \pm 5.32^{\mathrm{A}}$ & $-48.02 \pm 2.51^{\mathrm{A} a}$ & $10.10 \pm 0.06^{\mathrm{BC}}$ & $10.05 \pm 0.05^{\mathrm{C}}$ & $11.02 \pm 0.01$ & $11.26 \pm 0.25$ \\
\hline
\end{tabular}

Means within the same column having different superscripts (capital letter) are significantly different at $p<0.05$.

Means within the same row having different superscripts (lowercase letter) are significantly different at $p<0.05$.

All values were expressed as mean \pm standard error $(n=3)$. 

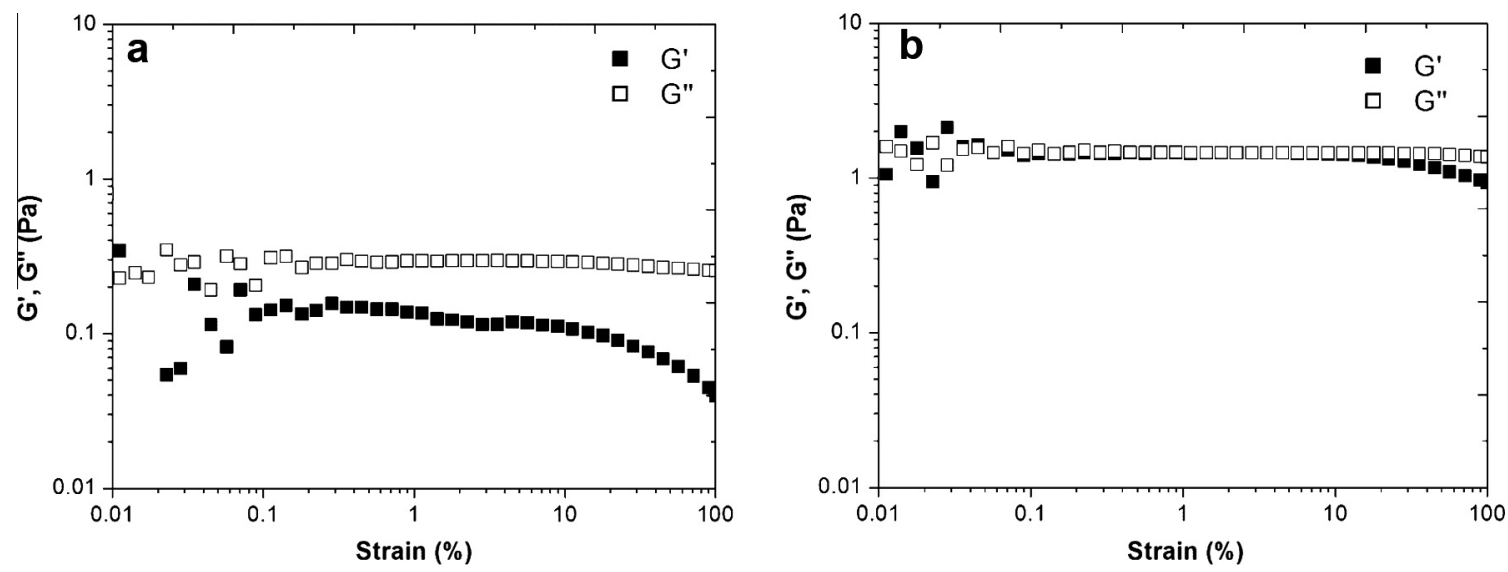

Fig. 4. Typical $G^{\prime}, G^{\prime \prime}$ vs. strain curves obtained for NFS using $2 \mathrm{~g}$ (a) and $4 \mathrm{~g}$ (b) of cassava starch, both with $0 \%$ in laponite concentration.
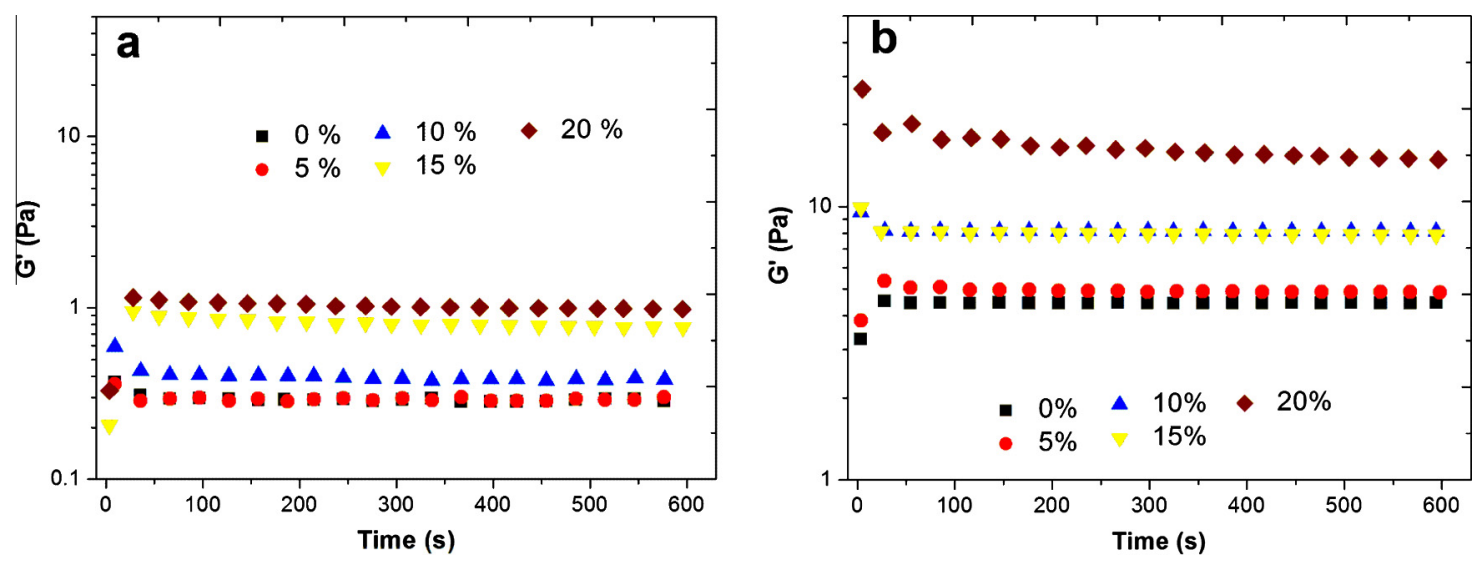

Fig. 5. Typical $G^{\prime}$ vs. time curves obtained for NFS using $2 \mathrm{~g}$ (a) and $4 \mathrm{~g}$ (b) of cassava starch to different laponite concentrations.

after 2 min, and that more concentrated NFS show a decrease in $G^{\prime}$ at earlier times. Thus, for all remaining rheological testing of NFS, an equilibrium time of $2 \mathrm{~min}$ after the pre-shear was applied before further rheological characterization.

The mechanical spectra of all NFS are presented in Fig. 6. For NFS with $2 \mathrm{~g}$ of cassava starch, the measured frequency range is from 0.63 to $6.3 \mathrm{rad} / \mathrm{s}$, whereas it is from 0.63 to $31.5 \mathrm{rad} / \mathrm{s}$ for NFS with $4 \mathrm{~g}$ of cassava starch. The range of frequencies depends on limitations in torque sensitivity (lower frequencies) and rheometer inertia (larger frequencies). Examining the frequency response displayed in Fig. 6 , it can be seen that the $C_{\text {Lap }}$ has a strong effect on the structure of NFS. A typical liquid-like response with $G^{\prime \prime}>G^{\prime}$ for the whole frequency range tested is observed in NFS with 2 g cassava starch and low $C_{\text {Lap }}$ (up to 5\%). For all remaining systems, mechanical spectra typical of viscoelastic solids or gels $\left(G^{\prime}>G^{\prime \prime}\right)$ are measured. These results are consistent with those of Jorge et al. (2014) who also find a sol-gel transition for montmorillonite/gelatin systems with increasing clay content.
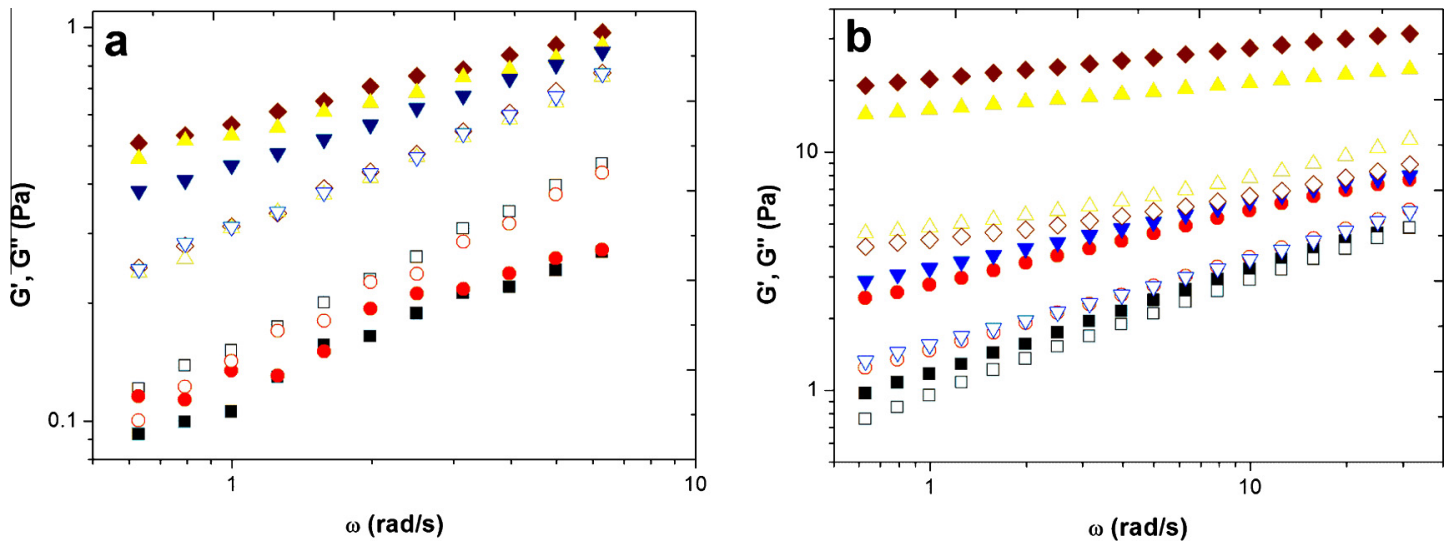

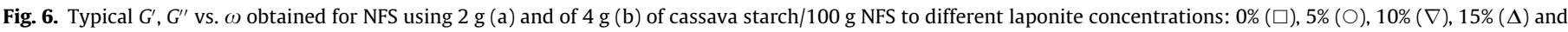
$20 \%(\diamond)$. Solid and empty symbols denote $G^{\prime}$ and $G^{\prime \prime}$, respectively. 
Power law model (Eqs. (1) and (2)) described adequately the frequency dependence of the $G^{\prime}$ and $G^{\prime \prime}$ moduli in NFS:

$$
\begin{aligned}
& G^{\prime}(\omega)=K^{\prime} \omega^{n^{\prime}} \\
& G^{\prime \prime}(\omega)=K^{\prime \prime} \omega^{n^{\prime \prime}}
\end{aligned}
$$

where $\omega$ is the angular frequency $(\mathrm{rad} / \mathrm{s})$. The, $K^{\prime}, K^{\prime \prime}, n^{\prime}$ and $n^{\prime \prime}$ parameters were fitted to the data and computed values are shown in Table 2.

For NFS with the same cassava starch concentration, the increase in $C_{\text {Lap }}$ leads in $K^{\prime}$ values much larger than those of $K^{\prime \prime}$ values, suggesting a more solid-like elastic behavior (Song et al., 2006). In addition, $n^{\prime}$ and $n^{\prime \prime}$ values decreased with the increase in $C_{\text {Lap }}$, indicating that the frequency dependence in NFS becomes weaker with the increase in $C_{\text {Lap }}$. Thus laponite promotes the solid-like elastic behavior (Song et al., 2006). Note here that the addition of laponite does not simply correspond to a reinforcing effect, since the latter would give an increase in both moduli, with no change in the frequency dependence. Instead, the change in the frequency dependence mirrored in the change in both $n^{\prime}$ and $n^{\prime \prime}$ with $C_{\text {Lap }}$ suggests a structural modification of the nanocomposites with the laponite load. A quantitative analysis of the effect of the addition of laponite on NFS elasticity was proposed in Fig. 7 where the storage modulus measured at $1 \mathrm{rad} / \mathrm{s}$ from curves displayed in Fig. 6 was plotted as a function of the total solid content in NFS (Fig. 7a) or of the relative content in laponite (Fig. 7b). Data for NFS formulated with $2 \mathrm{~g}$ cassava starch and $5 \%$ or $10 \%$ laponite are not presented in Fig. 7a since these two systems show liquid like behavior, whereas Fig. 7 compares solid like NFS. The increase of gel elasticity with total solid content is much smaller for NFS formulated with $2 \mathrm{~g}$ cassava starch when compared with NFS prepared with $4 \mathrm{~g}$ cassava starch. This result suggests that laponite has a different reinforcing effect for the two systems. Indeed, the reinforcing effect of laponite is more efficient with $4 \mathrm{~g}$ cassava starch as the increase in gel elasticity is steeper. For these gels, we can compare the reinforcing effect of laponite on the cassava gel matrix with the Maron and Pierce equation (Eq. (3)) originally devised for Newtonian fluids but successfully applied to viscoelastic matrices (Barnes, 2003; Ghanbari et al., 2013):

$\sqrt{\frac{G_{0}^{\prime}}{G^{\prime}}}=1-\frac{C_{\text {Lap }}}{C_{m}}$

where $G_{0}^{\prime}$ is the storage modulus of the cassava starch matrix extracted at $1 \mathrm{rad} / \mathrm{s}$ from the mechanical spectra displayed in Fig. $6, C_{\text {Lap }}$ is the laponite content and $C_{m}$ is the content of laponite at which close packing of fillers occurs. Fig. $7 \mathrm{~b}$ shows the good agreement between Eq. (4) and the data, and the fitting of experimental data to Eq. (3) returns a $C_{m}=25 \mathrm{wt} \% \pm 2 \mathrm{wt} \%$. The following statement can be extracted from this analysis: laponite particles are reinforcing the cassava starch matrix without forming a laponite network since the latter should build up at weight fractions of the order of $25 \mathrm{wt} \%$. This also implies that laponite were well dispersed in the cassava starch matrix, as mirrored in the value of $C_{m}$ which is reminiscent from fillers with large aspect ratio (Barnes, 2003).

Curves obtained from the oscillatory stress sweep tests are presented in Fig. 8 for selected $C_{\text {Lap. }}$ NFS with $2 \mathrm{~g}$ cassava starch shows a shear thinning behavior which is more pronounced for the elastic modulus $G^{\prime}$. However, the behavior switches to a weak thickening at the largest oscillatory stresses tested. The thickening is more apparent upon addition of $20 \mathrm{wt} \%$ laponite and occurs at smaller stresses. Similarly, the onset of non-linear dynamic behavior occurs at smaller stresses. The picture is somehow different for the NFS prepared with $4 \mathrm{~g}$ cassava starch (Fig. 8b). Adding laponite to the cassava starch gel extends the regime of linear viscoelastic behavior by nearly one decade as the NFS with $20 \mathrm{wt} \%$ laponite sustains stresses as large as $4 \mathrm{~Pa}$, whereas the cassava starch gel starts thinning at $0.2 \mathrm{~Pa}$. Moreover, and in contrast to NFS with $2 \mathrm{~g}$ which keeps essentially a shear thinning behavior of both $G^{\prime}$ and $G^{\prime \prime}$ for all laponite contents tested, the addition of laponite to the NFS matrix prepared with $4 \mathrm{~g}$ cassava starch is accompanied by a change from thinning to thickening which is particularly evident in $G^{\prime \prime}$.

\subsubsection{Steady shear properties}

NFS were studied with steady shear tests in the aim of evaluating the spread ability of the solutions and assess their suitability to knife coating application.

Decreasing and increasing flow curves showed similar flow behavior for shear rate between 0.1 and $200 \mathrm{~s}^{-1}$. In others words, no hysteresis behavior was observed in NFS. This result suggests that within 2 min testing, no thixotropy could be observed. Flow curves of NFS with $2 \mathrm{~g}$ cassava starch showed a pseudoplastic or shear-thinning behavior (Fig. 9a), that was well fitted to Herschel-Bulkley model $\left(R^{2} \geqslant 0.98\right)$ (Eq. (4)).

$\tau=\tau_{o}+k \dot{\gamma}^{n}$

where $\tau_{o}$ is the yield stress (Pa), $k$ is the consistency coefficient $\left(\mathrm{Pa} \mathrm{s}^{n}\right)$ and $n$ the flow behavior index (dimensionless). All parameters computed from the fitting of Eq. (4) to the data in Fig. 9 are shown in Table 3.

The addition of laponite up to $5 \mathrm{wt} \%$ has little effect on the shear thinning behavior of NFS prepared with $2 \mathrm{~g}$ cassava starch. For larger laponite loading, a gel is formed and thus a significant yield

Table 2

\begin{tabular}{|c|c|c|c|c|c|c|c|}
\hline \multirow[t]{2}{*}{$C_{C S}(\% \mathrm{w} / \mathrm{w})$} & \multirow[t]{2}{*}{$C_{\text {Lap }}(\% \mathrm{w} / \mathrm{w})$} & \multicolumn{3}{|l|}{$G^{\prime}$} & \multicolumn{3}{|l|}{$G^{\prime \prime}$} \\
\hline & & $\overline{K^{\prime}}$ & $n^{\prime}$ & $R^{2}$ & $\overline{K^{\prime \prime}}$ & $n^{\prime \prime}$ & $R^{2}$ \\
\hline \multirow[t]{5}{*}{2} & 0 & $0.33 \pm 0.03^{C}$ & $0.44 \pm 0.03^{\mathrm{A}}$ & 0.99 & $0.48 \pm 0.01^{\mathrm{B}}$ & $0.60 \pm 0.01^{\mathrm{A}}$ & 0.99 \\
\hline & 5 & $0.21 \pm 0.04^{C}$ & $0.44 \pm 0.04^{\mathrm{A}}$ & $0.96-097$ & $0.41 \pm 0.03^{\mathrm{B}}$ & $0.64 \pm 0.02^{\mathrm{A}}$ & 0.99 \\
\hline & 10 & $0.73 \pm 0.01^{\mathrm{B}}$ & $0.40 \pm 0.00^{\mathrm{AB}}$ & 0.99 & $0.72 \pm 0.01^{\mathrm{A}}$ & $0.50 \pm 0.01^{\mathrm{B}}$ & 0.99 \\
\hline & 15 & $0.94 \pm 0.04^{\mathrm{A}}$ & $0.30 \pm 0.01^{\mathrm{BC}}$ & 0.99 & $0.78 \pm 0.02^{\mathrm{A}}$ & $0.49 \pm 0.01^{\mathrm{B}}$ & 0.99 \\
\hline & 20 & $0.97 \pm 0.00^{\mathrm{A}}$ & $0.28 \pm 0.00^{\mathrm{C}}$ & 0.99 & $0.75 \pm 0.00^{\mathrm{A}}$ & $0.48 \pm 0.00^{\mathrm{B}}$ & 0.99 \\
\hline \multirow[t]{5}{*}{4} & 0 & $2.76 \pm 0.12^{\mathrm{D}}$ & $0.41 \pm 0.0^{\mathrm{A}}$ & 0.99 & $2.33 \pm 0.03^{\mathrm{D}}$ & $0.46 \pm 0.00^{\mathrm{A}}$ & 0.99 \\
\hline & 5 & $4.90 \pm 0.02^{\mathrm{CD}}$ & $0.31 \pm 0.00^{\mathrm{AB}}$ & 0.99 & $3.07 \pm 0.03^{C}$ & $0.40 \pm 0.00^{\mathrm{B}}$ & 0.99 \\
\hline & 10 & $6.90 \pm 1.08^{\mathrm{BC}}$ & $0.24 \pm 0.02^{\mathrm{BC}}$ & 0.99 & $3.41 \pm 0.22^{C}$ & $0.34 \pm 0.00^{C}$ & 0.99 \\
\hline & 15 & $7.65 \pm 0.19^{\mathrm{B}}$ & $0.20 \pm 0.00^{\mathrm{BC}}$ & 0.99 & $3.13 \pm 0.00^{\mathrm{B}}$ & $0.32 \pm 0.00^{C}$ & 0.99 \\
\hline & 20 & $14.04 \pm 0.07^{\mathrm{A}}$ & $0.13 \pm 0.00^{C}$ & 0.99 & $3.85 \pm 0.11^{\mathrm{A}}$ & $0.22 \pm 0.00^{\mathrm{D}}$ & $0.94-0.98$ \\
\hline
\end{tabular}

Parameters ${ }^{*}$ of the Power Law model calculated by fitting data on $G^{\prime}, G^{\prime \prime}$ vs. $\omega$ in NFS.

$C_{C S}=$ cassava starch concentration; $C_{\text {Lap }}=$ laponite concentration.

Means within the same column having different superscripts (capital letter) are significantly different at $p<0.05$.

All values were expressed as mean \pm standard error $(n=3)$. 

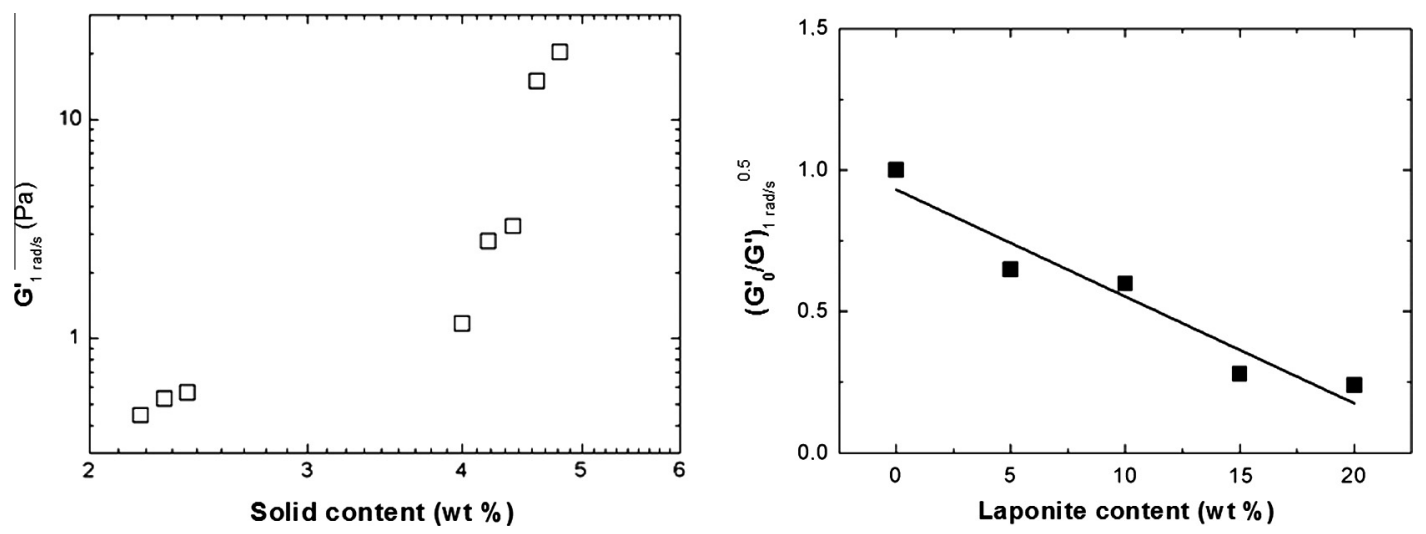

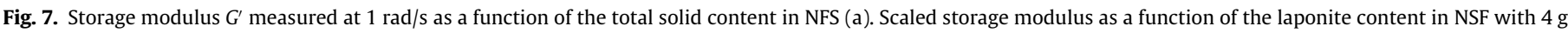
starch (b). Line is a fit of Eq. (1) to the data.
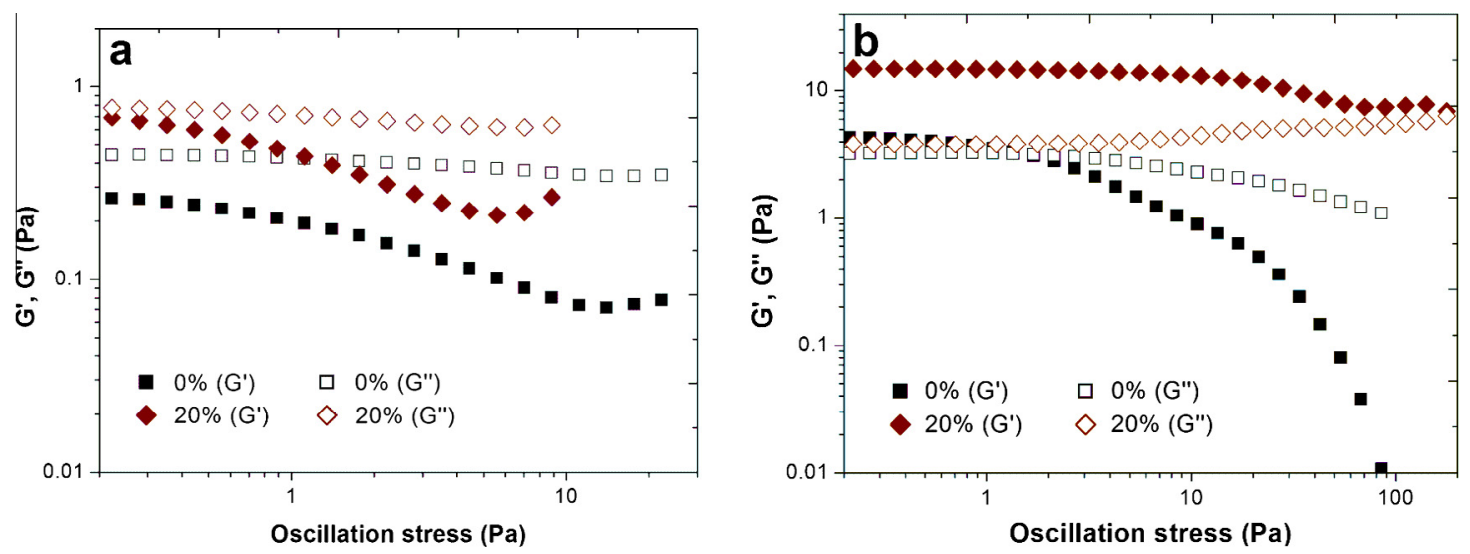

Fig. 8. Typical $G^{\prime}$ vs. oscillatory stress obtained for NFS using $2 \mathrm{~g}$ (a) and of $4 \mathrm{~g}$ (b) of cassava starch and two laponite concentrations.
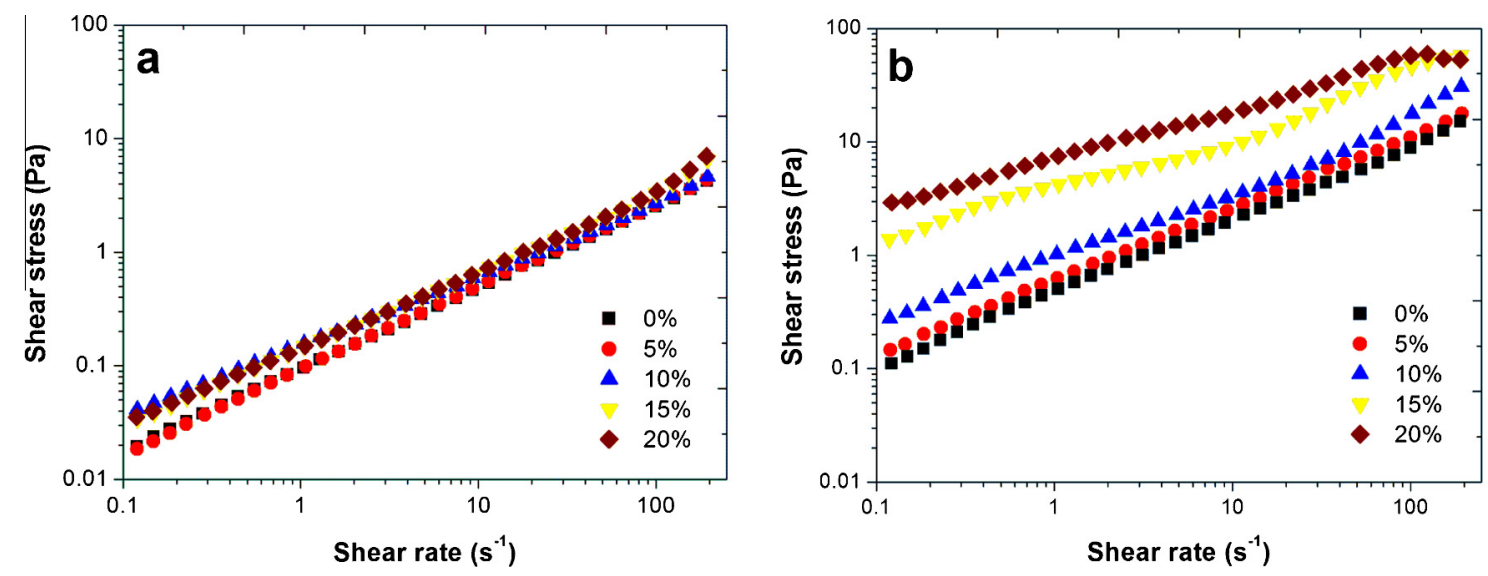

Fig. 9. Flow curves for NFS using $2 \mathrm{~g}$ (a) and $4 \mathrm{~g}$ (b) of cassava starch/100 g NFS to different laponite concentrations.

stress is obtained. Parameters reported in Table 3 however suggest that the laponite amount does not really affect the spread ability of NFS. The increase from $2 \mathrm{~g}$ to $4 \mathrm{~g}$ cassava starch in NFS free of laponite is related to an increase of intermolecular forces that restrict molecular motion in amylose and amylopectin chains (Che et al., 2008). Thus, a gel is formed as shown above, and a 10 times larger yield stress is measured. An increase in the yield stress with the laponite concentration is also evident, which indicates that laponite will not favor the spread ability of the NFS. According to
Gardini et al. (2010), systems with shear-thinning behavior can be successfully spread. When the systems have a low enough viscosity, the shear rate to use to spread is similar to used in casting process. In contrast, low-shear stresses are used for systems with higher viscosity.

It is well accepted that laponite can have a cross-linking action on polymers and biopolymers, developing network structures where the polymer chains are attached to the surface of clay sheets (Haraguchi and Li, 2006; Tang and Alavi, 2012). Hence 
Table 3

Parameters* of the Herscel-Bulkley model calculated by fitting data on shear rate vs. shear stress curves in NFS.

\begin{tabular}{llllll}
\hline $\begin{array}{l}\mathrm{C}_{\mathrm{CS}} \\
(\% \mathrm{w} / \mathrm{w})\end{array}$ & $\begin{array}{l}\mathrm{C}_{\mathrm{Lap}} \\
(\% \mathrm{w} / \mathrm{w})\end{array}$ & $\begin{array}{l}\tau_{o} \\
\left(\mathrm{~Pa} \times 10^{2}\right)\end{array}$ & $\begin{array}{l}k \\
\left(\mathrm{~Pa} \mathrm{~s}^{n} \times 10^{2}\right)\end{array}$ & \multicolumn{1}{l}{$\begin{array}{l}\left(\times 10^{2}\right) \\
R^{2}\end{array}$} & $R^{2}$ \\
\hline 2 & 0 & $2.01 \pm 0.12^{\mathrm{B}}$ & $8.74 \pm 0.05^{\mathrm{C}}$ & $73.4 \pm 0.10^{\mathrm{A}}$ & 0.99 \\
& 5 & $2.09 \pm 0.21^{\mathrm{B}}$ & $9.08 \pm 0.05^{\mathrm{C}}$ & $73.2 \pm 0.05^{\mathrm{A}}$ & 0.99 \\
& 10 & $2.63 \pm 0.09^{\mathrm{A}}$ & $11.46 \pm 0.10 \mathrm{~A}^{\mathrm{B}}$ & $70.02 \pm 2.33^{\mathrm{C}}$ & 0.99 \\
& 15 & $2.71 \pm 0.05^{\mathrm{A}}$ & $11.33 \pm 0.88^{\mathrm{AB}}$ & $70.20 \pm 0.30^{\mathrm{C}}$ & 0.99 \\
& 20 & $2.60 \pm 0.06^{\mathrm{A}}$ & $12.63 \pm 0.10^{\mathrm{A}}$ & $70.73 \pm 0.07^{\mathrm{B}}$ & 0.99 \\
& 0 & $9.10 \pm 0.59^{\mathrm{C}}$ & $43.00 \pm 0.33^{\mathrm{C}}$ & $71.00 \pm 1.15^{\mathrm{A}}$ & 0.99 \\
& 5 & $10.00 \pm 0.51^{\mathrm{C}}$ & $39.20 \pm 2.65^{\mathrm{C}}$ & $69.30 \pm 1.95^{\mathrm{AB}}$ & 0.99 \\
& 10 & $15.10 \pm 0.06^{\mathrm{C}}$ & $88.97 \pm 0.80^{\mathrm{C}}$ & $69.00 \pm 0.60^{\mathrm{B}}$ & 0.99 \\
& 15 & $99.03 \pm 1.08^{\mathrm{B}}$ & $275.02 \pm 42.20^{\mathrm{B}}$ & $67.50 \pm 0.50^{\mathrm{BC}}$ & 0.98 \\
& 20 & $235.25 \pm 14.74^{\mathrm{A}}$ & $450.67 \pm 10.73^{\mathrm{A}}$ & $63.18 \pm 3.08^{\mathrm{C}}$ & 0.99 \\
\hline
\end{tabular}

$C_{C S}=$ cassava starch concentration; $C_{\text {Lap }}=$ laponite concentration.

All fit parameters ( $\tau_{o}, k$ and $) n$ in NFS with $4 \mathrm{~g}$ of cassava starch and laponite content $>5 \%$ were fitted for a shear rate range between $0.1 \mathrm{~s}^{-1}$ and $1 \mathrm{~s}^{-1}$.

Means within the same column having different superscripts (capital letter) are significantly different at $p<0.05$.

All values were expressed as mean \pm standard error $(n=3)$.

cross-linking interactions between amylose-laponite and amylopectin-laponite may be the main reason for the increasing in pseudoplasticity in NFS when laponite was added. For laponite in excess of $5 \mathrm{wt} \%$, the flow curves in Fig. 9b departs from the monotonic shear thinning predicted with Eq. (4). Instead, the stress tends to plateauing at intermediate shear rates (this is more evident with $15 \mathrm{wt} \%$ laponite). As a result, parameters in Table 3 where computed form the fitting of Eq. (4) to data ranging only from $0.1 \mathrm{~s}^{-1}$ to $1 \mathrm{~s}^{-1}$.

\section{Conclusions}

In this research, nanocomposites-forming solutions had been successfully developed using cassava starch and laponite.

Laponite was dispersed in distilled water by means of ultraturrax, different speeds (rpm) and homogenization time led to different particle size distributions. A notable decrease in particle size was observed for speed rotations at 10,000 and $15,000 \mathrm{rpm}$ for $60 \mathrm{~min}$. However no difference in particle size was observed for speed rotations at 20,000 and $23,000 \mathrm{rpm}$ with the increase in time. These speeds and time combinations led to obtain laponite particles with size $<80 \mathrm{~nm}$. The presence of elementary particle disk-shape was confirmed by AFM images.

Laponite nanoparticles had a strong effect on the $G^{\prime}$ and $G^{\prime \prime}$ values in NFS. With the increase in laponite concentration $\left(C_{\text {Lap }}\right)$, NFS shifts from a viscoelastic liquid like to a solid-like elastic behavior, or the cassava starch network that forms a gel is reinforced by the addition of laponite. Analysis of the increase in gel elasticity with $C_{\text {Lap }}$ with a model suggests that laponite remained well dispersed in the NFS. The knowledge of the rheological properties of these systems is important to control the NFS application on support. Flow curves confirmed the effect of laponite on the network structures in NFS. Flow curves also indicate that for the NFS with a larger content of cassava starch, the addition of laponite does not favor the spread ability of NFS.

\section{Acknowledgments}

The authors gratefully acknowledges to São Paulo Research Foundation (FAPESP) for the PhD fellowship of the first author (2012/24047-3) and for the grant (2013/07914-8).

\section{References}

Abou, B., Bonn, D., Meunier, J., 2003. Nonlinear rheology of laponite suspensions under an external drive. J. Rheol. 47, 979-988.

Aouada, F.A., Mattoso, L.H.C., Longo, E., 2011. A simple procedure for the preparation of laponite and thermoplastic starch nanocomposites: structural, mechanical, and thermal characterizations. J. Thermoplastic Compos. Mater. 26, 109-124.

Balnois, E., Vidal, S.D., Levitz, P., 2003. Probing the morphology of laponite Clay colloids by atomic force microscopy. Langmuir 19, 6633-6637.

Barnes, H.A., 2003. A review of the rheology of filled viscoelastic systems. Rheol. Rev., 1-36

Bippus, L., Jaber, M., Lebeau, B., 2009. Laponite and hybrid surfactant/laponite particles processed as spheres by spray-drying. New J. Chem. 33, 1116-1126.

Che, L.M., Li, D., Wang, L.J., Özkan, N., Chen, X.D., Mao, Z.H., 2008. Rheological properties of dilute aqueous solutions of cassava starch. Carbohyd. Polym. 74, 385-389.

Chen, C.H., Kuo, W.S., Lai, L.S., 2009. Rheological and physical characterization of film forming solutions and edible films from tapioca starch/decolorized hsiantsao leaf gum. Food Hydrocolloids 23, 2132-2140.

Chung, Y.L., Ansari, S., Estevez, L., Hayrapetyan, S., Giannelis, E.P., Lai, H.M., 2010. Preparation and properties of biodegradable starch-clay nanocomposites. Carbohyd. Polym. 79, 391-396.

Cummins, H.Z., 2007. Liquid, glass, gel: the phases of colloidal laponite. J. NonCristalline Solids 353, 3891-3905.

Cyras, V.P., Manfredi, L.B., That, M.T.T., Vásquez, A., 2008. Physical and mechanical properties of thermoplastic starch/montmorillonite nanocomposite films. Carbohyd. Polym. 73, 55-63.

Daniel, L.M., Frost, R.L., Zhu, H.Y., 2007. Synthesis and characterization of claysupported titania photocatalysts. J. Colloid Surf. Sci. 316, 72-79.

Flaker, C.H.C., Lourenço, R.V.,Bittante, A.M.Q.B., Sobral, P.J.A., 2015. Gelatin-based nanocomposite films: a study on montmorillonite dispersion methods and concentration. J. Food Eng., In press. http://dx.doi.org/10.1016/j.jfoodeng.2014. 11.009.

Gardini, G., Deluca, M., Nagliati, M., Galassi, C., 2010. Flow properties of PLZTN aqueous suspensions for tape casting. Cera. Int. 36, 1687-1696.

Ghanbari, A., Heuzey, M.C., Carreau, P.J., Ton-That, M.T., 2013. Morphological and rheological properties of PET/clay nanocomposites. Rheol. Acta 52, 59-74.

Haraguchi, K., Li, H.J., 2006. Mechanical properties and structure of polymer-clay nanocomposite gels with high clay content. Macromolecules 39, 1898-1905.

Haraguchi, K., Li, H.J., Matsuda, K., Takehisa, T., Elliott, E., 2005. Mechanism of forming organic/inorganic network structures during in-situ free-radical polymerization in PNIPA-clay nanocomposite hydrogels. Macromolecules 38, 3482-3490.

Hassanabadi, M.H., Rodrigue, D., 2012. Relationships between linear and nonlinear shear response of polymer nano-composites. Rheolo. Acta 51, 991-1005.

Herrera, N.N., Letoffe, J.M., Putaux, J.L., David, L., Lami, E.B., 2004. Aqueous dispersions of silane-functionalized laponite clay platelets. A first step toward the elaboration of water-based polymer/clay nanocomposites. Langmuir 20, 1564-1571.

Jorge, M.F.C., Flaker, C.H.C., Nassar, S.F., Moraes, I.Z.F., Bittante, A.M.Q.B., Sobral, P.J.A., 2014. Viscoelastic and rheological properties of nanocomposite-forming solutions based on gelatin and montmorillonite. J. Food Eng. 120, 81-87.

Joshi, Y.M., Reddy, G.R.K., Kulkarni, A.L., Kumar, N., Chhabra, R.P., 2008. Rheological behaviour of aqueous suspensions of laponite: new insights into the ageing phenomena. Proc. Royal Soc. A 464, 469-489.

Kasirga, Y., Oral, A., Caner, C., 2012. Preparation and characterization of chitosan/montmorillonite-K10 nanocomposites films for food packaging applications. Polym. Compos. 33, 1874-1882.

Kumar, N.V.N., Muralidhar, K., Joshi, Y.M., 2008. On the refractive index of ageing dispersions of laponite. Appl. Clay Sci. 42, 326-330.

Levitz, P., Lecolier, E., Mourchid, A., Delville, A., Lyonnard, S., 2000. Liquid-solid transition of laponite suspensions at very low ionic strength: long-range electrostatic stabilization of anisotropic colloids. Europhys. Lett. 49, 672-677.

Moraes, I.C.F., Carvalho, R.A., Bitante, A.M.Q.B., Solorza-Feria, J., Sobral, P.J.A., 2009. Film forming solution based on gelatin and poly(vinil alcohol) blends: thermal and rheological characterizations. J. Food Eng 95, 588-596.

Nicolai, T., Cocard, S., 2000. Light scattering study of the dispersion of laponite. Langmuir 16, 8189-8193.

Park, J.H., Park, S.M., Kim, Y.H., Oh, W., Lee, G.W., Karim, M.R., Park, J.H., Yeum, J.Y., 2012. Effect of montmorillonite on wettability and microstructure properties of zein/montmorillonite nanocomposite nanofiber mats. J. Compos. Mater., 1-7

Perotti, G.F., Barud, H.S., Messaddeq, Y., Ribeiro, S.J.L., Constatino, V.R.L., 2011. Bacterial cellulose-laponite clay nanocomposites. Polymer 52, 157-163.

Perotti, G.F., Tronto, J., Bizeto, M.A., Izumi, C.M.S., Temperini, M.L.A., Lugão, A.B., Parra, D.F., Constantino, V.R.L., 2014. Biopolymer-clay nanocomposites: cassava starch and synthetic clay cast films. J. Brazil. Chem. Soc. 25, 320-330.

Shibayama, M., Suda, J., Karino, T., Okabe, S., Takehisa, T., Haraguchi, K., 2004. Structure and dynamics of poly( $\mathrm{N}$-isopropylacrylamide)-clay nanocomposite gels. Macromolecules 37, 9606-9612.

Song, K.W., Kuk, H.Y.K., Chang, G.S., 2006. Rheology of concentrated xanthan gum solutions: oscillatory shear flow behavior. Korea-Austr. Rheol. J. 18, 67-81.

Tang, X., Alavi, S., 2012. Structure and physical properties of starch/poly vinyl alcohol/laponite RD nanocomposites films. J. Agric. Food Chem. 60, 1954-1962. 